\title{
FAKTOR PENGHAMBAT RELEVANSI PENEMPATAN PKL DITINJAU DARI PIHAK SEKOLAH DAN DU/DI BESERTA CARA MENGATASINYA DI SMK SE-JOMBANG
}

\author{
Rizka Rahmi Saputri'), Setiadi Cahyono Putro'), Yuni Rahmawati ${ }^{3)}$ \\ 1, 2, 3 Fakultas Teknik, Universitas Negeri Malang \\ email: rizkarahmisaputri25@gmail.com, setiadi.cahyono.ft@um.ac.id, yuni.rahmawati.ft@um.ac.id
}

\begin{abstract}
Abstrak
Penelitian ini bertujuan untuk mengetahui tingkat relevansi penempatan PKL di SMK se-Jombang, mengidentifikasi faktor penghambat relevansi penempatan PKL ditinjau dari pihak sekolah dan DU/DI di SMK se-Jombang, dan mengetahui cara mengatasi faktor penghambat relevansi penempatan PKL ditinjau dari pihak sekolah dan DU/DI di SMK se-Jombang. Penelitian ini menggunakan pendekatan kuantitatif jenis deskripstif dengan teknik pengumpulan data wawancara dan angket. Hasil penelitian memaparkan bahwa tingkat relevansi penempatan PKL di SMK se-Jombang Kompetensi Keahlian Teknik Komputer dan Jaringan serta Multimedia sebesar $55,39 \%$ dalam kategori rendah. Faktor penghambat relevansi penempatan PKL ditinjau dari pihak sekolah yaitu (a) tahap perencanaan sebesar $22,78 \%$ dalam kategori rendah; (b) tahap pelaksanaan sebesar 42,76 dalam kategori cukup; dan (c) tahap evaluasi sebesar $23,82 \%$ dalam kategori rendah. Faktor penghambat relevansi penempatan PKL ditinjau dari DU/DI yaitu (a) tahap perencanaan sebesar 30,24\% dalam kategori rendah; (b) tahap pelaksanaan sebesar 35,86 dalam kategori rendah; dan (c) tahap evaluasi sebesar 50,60\% dalam kategori cukup.
\end{abstract}

Kata kunci: relevansi penempatan PKL, faktor penghambat, cara mengatasi, SMK, DU/DI.

\begin{abstract}
This study aims to determine the relevance level of the placement of PKL at Vocational High School in Jombang, identifying factors inhibiting the relevance of PKL placement in terms of school and DU/DI at Vocational High School in Jombang, and knowing how to overcome the factors inhibiting the relevance of PKL placement in terms of school and DU/DI at Vocational High School in Jombang. This study uses quantitative approach descriptive type with data collection techniques of interviews and questionnaires. The results of research show that the relevance level of the placement of PKL at Vocational High School in Jombang Competency of Computer Engineering and Networking and Multimedia is 55.39\% in low category. Factors inhibiting the relevance of PKL placement in terms of the school side are (a) planning stage of $22.78 \%$ in low category; (b) the implementation stage of 42.76 in sufficient category; and (c) evaluation stage of $23.82 \%$ in low category. Factors inhibiting the relevance of PKL placement in terms of DU/DI are (a) planning stage of $30.24 \%$ in low category; (b) the implementation stage of 35.86 in the low category; and (c) evaluation stage of $50.60 \%$ in sufficient category.
\end{abstract}

Keywords: relevance of PKL placement, inhibiting factor, how to overcome, SMK, $D U / D I$

\section{PENDAHULUAN}

Sekolah Menengah Kejuruan (SMK) merupakan pendidikan yang dibentuk untuk mengembangkan kemampuan dan keterampilan peserta didik dalam memasuki dunia kerja. Menurut Starr (1986), SMK berkesinambungan dengan dunia kerja atau Dunia Usaha dan Dunia Industri (DU/DI), maka Praktik Kerja Lapangan (PKL) memegang peranan kunci. Keterampilan kerja hanya dapat diajarkan dengan baik jika mereka dilatih secara langsung dengan peralatan sebenarnya (Reiser \& Gagne, 1982). SMK dapat mening- 
katkan kompetensi peserta didiknya jika telah melaksanakan PKL (Iriani \& Soeharto, 2015). Jadi kemampuan dan keterampilan kerja peserta didik hanya berhasil diajarkan melalui praktik kerja di DU/DI sesuai dengan kompetensi keahlian.

Menurut Widyasari (2017), kompetensi adalah kemampuan dan keterampilan yang dimiliki seseorang agar perilaku kognitif, afektif, dan psikomotorik dapat dilakukan dengan baik. Kompetensi adalah kemampuan yang dimiliki seseorang yang diperoleh melalui proses pembelajaran dan pengalaman. DU/DI merupakan lembaga swasta atau instansi Pemerintah atau masyarakat yang membuat dan/atau menjual barang dan/atau jasa dan memiliki sumber daya (Kepmendikbud RI nomor 323/U/1997 pasal 1, ayat 3).

PKL merupakan program yang harus dilaksanakan oleh SMK dan wajib diikuti oleh peserta didik (UU RI No. 20 Tahun 2003). Kegiatan PKL diharapkan peserta didik dapat mengembangkan kemampuan dalam mengaplikasikan pelajaran yang telah didapatkan di sekolah, sehingga tujuan PKL dapat terwujud. Namun dalam pelaksanaannya, PKL justru tidak menunjukkan hasil yang maksimal. Kesesuaian tempat PKL dengan kompetensi keahlian peserta didik terkadang kurang diperhatikan, padahal kesesuaian tempat PKL menjadi dasar keberhasilan pencapaian kompetensi keahlian dengan hasil PKL. Apabila memperhatikan kesesuaian tempat PKL dengan kompetensi keahlian, peserta didik tidak akan menganggur dan tidak mengerjakan pekerjaan yang tidak sesuai dengan kompetensi keahlian saat menjalani PKL di DU/DI.

Relevansi atau kesesuaian merupakan masalah yang cukup esensil dan harus mendapatkan perhatian dalam membangun kurikulum (Hamalik, 2013). Melalui PKL peserta didik akan memperoleh pengalaman untuk meningkatkan kompetensi sesuai dengan kompetensi keahliannya (Fatchurrochman, 2017). Relevansi antara tempat belajar di sekolah dan DU/DI harus diciptakan agar proses pembelajaran dapat dilakukan secara optimal (Setianingtyas, dkk., 2013:60)
Penghambat dalam PKL terdiri dari aspek kendala peserta didik dan kendala pembimbing (Prasetyo, 2013). Kendala peserta didik meliputi kurangnya pengarahan, perbedaan materi pelajaran di sekolah dengan DU/DI. Kendala pembimbing meliputi pembingan secara intensif. Indaryanto (dalam Hadi, 2017) menambahkan dalam penelitiannya penghambat yang ditemui dalam PKL antara lain: (1) jenis pekerjaan yang diberikan kepada peserta PKL kurang sesuai dengan kompetensi yang dimiliki; (2) tempat PKL yang jauh dari tempat tinggal peserta didik mengakibatkan peserta didik kesulitan menuju tempat PKL; dan (3) kurang optimalnya pembimbingan dan monitoring yang dilakukan oleh pihak sekolah.

Kendala yang dialami ketika pelaksanaan PKL adalah materi pelajaran yang belum disampaikan di sekolah, tetapi DU/DI menuntut untuk mengerjakannya. Mangkunegara (2003:111) juga menyatakan bahwa "... tidak adanya relevansi dengan tuntutan dunia kerja, sering mengakibatkan sukarnya lulusan dalam menghadapi tuntutan dunia kerja". Permasalahan lainnya, yaitu kepercayaan DU/DI terhadap kompetensi peserta didik masih sangat rendah dan tempat PKL tidak sesuai dengan program keahlian (Putriatama, dkk., 2016).

Penelitian ini bertujuan untuk mengetahui tingkat relevansi penempatan PKL di SMK se-Jombang, mengidentifikasi faktor penghambat relevansi penempatan PKL ditinjau dari pihak sekolah di SMK se-Jombang, mengidentifikasi faktor penghambat relevansi penempatan PKL ditinjau dari DU/DI di SMK seJombang, mengetahui cara mengatasi faktor penghambat relevansi penempatan PKL ditinjau dari pihak sekolah di SMK seJombang dan mengetahui cara mengatasi faktor penghambat relevansi penempatan PKL ditinjau dari DU/DI di SMK seJombang.

\section{METODE}

Metode penelitian yang digunakan dalam penelitian ini adalah metode penelitian kuantitatif jenis deskripstif. Populasi dalam penelitian ini adalah 4 Pokja PKL, 409 peserta didik kompetensi keahlian 
Teknik Komputer dan Jaringan, 160 peserta didik kompetensi keahlian Multimedia, dan 73 DU/DI mitra SMK di Jombang. Kemudian diambil sampel sebanyak 4 Pokja PKL dan 42 DU/DI yang bersedia untuk diwawancarai. Dengan teknik proportionate statisfied random sampling didapatkan sampel 202 peserta didik kompetensi keahlian Teknik Komputer dan Jaringan dan 114 peserta didik kompetensi keahlian Multimedia. Instrumen penelitian ini menggunakan wawancara dengan reliabilitas 0,935, dan 0,899 serta angket dengan reliabilitas 0,880 dan 0,760 .

\section{HASIL DAN PEMBAHASAN}

Tingkat relevansi penempatan $\mathrm{PKL}$ di SMK se-Jombang untuk kompetensi keahlian Teknik Komputer dan Jaringan serta Multimedia disajikan pada Tabel 1.

Tabel 1. Relevansi penempatan PKL di SMK se-Jombang

\begin{tabular}{lcccc}
\hline $\begin{array}{c}\text { Relevansi } \\
\text { Penempatan PKL }\end{array}$ & $\begin{array}{c}\text { Skor } \\
\text { Perolehan }\end{array}$ & $\begin{array}{c}\text { Skor } \\
\text { Maksimal }\end{array}$ & $\begin{array}{c}\text { Ketercapaian } \\
(\%)\end{array}$ & $\begin{array}{c}\text { Keterangan } \\
\text { Relevansi }\end{array}$ \\
\hline $\begin{array}{l}\text { Teknik Komputer dan } \\
\text { Jaringan }\end{array}$ & 12340 & 21008 & 58,74 & Rendah \\
Multimedia & 5933 & 11400 & 52,04 & Rendah \\
\hline & Rata-rata Relevansi & & 55,39 & Rendah \\
\hline
\end{tabular}

Berdasarkan Tabel 1 dapat dilihat bahwa rata-rata tingkat relevansi penempatan PKL di SMK se-Jombang untuk kompetensi keahlian Teknik Komputer dan Jaringan serta Multimedia sebesar 55,39\% dalam kategori rendah. Faktor penghambat tahap perencanaan PKL ditinjau dari pihak sekolah disajikan pada Tabel 2.

Tabel 2. Faktor penghambat tahap perencanaan PKL ditinjau dari pihak sekolah

\begin{tabular}{|c|c|c|c|c|c|}
\hline Indikator & $\begin{array}{c}\text { Skor } \\
\text { Perolehan }\end{array}$ & $\begin{array}{c}\text { Skor } \\
\text { Maksimal }\end{array}$ & $\begin{array}{c}\text { Pencapaian } \\
(\%)\end{array}$ & $\begin{array}{c}\text { Penghambat } \\
(\%)\end{array}$ & $\begin{array}{c}\text { Kategori } \\
\text { Penghambat }\end{array}$ \\
\hline $\begin{array}{l}\text { Perencanaan } \\
\text { Waktu PKL }\end{array}$ & 951 & 1280 & 74,30 & 25,70 & Rendah \\
\hline $\begin{array}{l}\text { Perencanaan } \\
\text { Tempat PKL }\end{array}$ & 981 & 1280 & 76,64 & 23,36 & Rendah \\
\hline $\begin{array}{l}\text { Perencanaan } \\
\text { Akomodasi } \\
\text { Peserta PKL }\end{array}$ & 899 & 1280 & 70,23 & 29,77 & Rendah \\
\hline $\begin{array}{l}\text { Pembekalan } \\
\text { peserta PKL }\end{array}$ & 1126 & 1280 & 87,97 & 12,03 & $\begin{array}{l}\text { Sangat } \\
\text { Rendah }\end{array}$ \\
\hline $\begin{array}{l}\text { Kerjasama } \\
\text { antara Pihak } \\
\text { Sekolah } \\
\text { dengan } \\
\text { DU/DI }\end{array}$ & 9 & 16 & 56,25 & 43,75 & Cukup \\
\hline Total & 3966 & 5136 & 77,22 & 22,78 & Rendah \\
\hline
\end{tabular}

Berdasarkan Tabel 2 total persentase indikator penghambat tahap perencanaan PKL ditinjau dari pihak sekolah $22,78 \%$ kategori penghambat rendah, sehingga dapat dikatakan tidak ada penghambat. Namun, pada indikator kerjasama antara pihak sekolah dengan DU/DI de- ngan persentase penghambat $43,75 \%$ kategori penghambat cukup, sehingga dapat dikatakan ada penghambat dalam hal kerjasama antara pihak sekolah dengan DU/DI. Faktor penghambat tahap pelaksanaan PKL ditinjau dari pihak sekolah disajikan pada Tabel 3. 
Tabel 3. Faktor penghambat tahap pelaksanaan PKL ditinjau dari pihak sekolah

\begin{tabular}{|c|c|c|c|c|c|}
\hline Indikator & $\begin{array}{c}\text { Skor } \\
\text { Perolehan }\end{array}$ & $\begin{array}{c}\text { Skor } \\
\text { Maksimal }\end{array}$ & $\begin{array}{c}\text { Ketercapaian } \\
(\%)\end{array}$ & $\begin{array}{l}\text { Penghambat } \\
(\%)\end{array}$ & $\begin{array}{l}\text { Keterangan } \\
\text { Penghambat }\end{array}$ \\
\hline $\begin{array}{l}\text { Fasilitas } \\
\text { yang } \\
\text { Diterima } \\
\text { Peserta PKL } \\
\text { sesuai } \\
\text { dengan } \\
\text { Kompetensi } \\
\text { Keahlian }\end{array}$ & 961 & 1264 & 76,03 & 23,97 & Rendah \\
\hline $\begin{array}{l}\text { Kompetensi } \\
\text { yang } \\
\text { Diterima } \\
\text { Peserta PKL } \\
\text { (Teknik } \\
\text { Komputer } \\
\text { dan } \\
\text { Jaringan) }\end{array}$ & 4990 & 10504 & 47,51 & 52,49 & Cukup \\
\hline $\begin{array}{l}\text { Kompetensi } \\
\text { yang } \\
\text { Diterima } \\
\text { Peserta PKL } \\
\text { (Multimedia) }\end{array}$ & 2091 & 5472 & 38,21 & 61,79 & Tinggi \\
\hline $\begin{array}{l}\text { Bimbingan } \\
\text { dan } \\
\text { Monitoring } \\
\text { yang } \\
\text { dilakukan } \\
\text { Pihak } \\
\text { Sekolah }\end{array}$ & 1747 & 2544 & 68,67 & 31,33 & Rendah \\
\hline $\begin{array}{l}\text { Pelaksanaan } \\
\text { PKL }\end{array}$ & 10227 & 15184 & 67,35 & 32,65 & Rendah \\
\hline Total & 20016 & 34968 & 57,24 & 42,76 & Cukup \\
\hline
\end{tabular}

Berdasarkan Tabel 3 total persentase indikator penghambat tahap pelaksanaan PKL ditinjau dari pihak sekolah $42,76 \%$ kategori penghambat cukup, sehingga dapat dikatakan ada penghambat. Penghambat pada indikator kompetensi yang diterima peserta PKL dengan persentase penghambat $52,49 \%$ kategori penghambat cukup untuk kompetensi keahlian Teknik Komputer dan Jaringan serta $61,79 \%$ kategori penghambat tinggi untuk kompetensi keahlian Multimedia. Faktor penghambat tahap evaluasi PKL ditinjau dari pihak sekolah disajikan pada Tabel 4. 
Tabel 4. Faktor penghambat tahap evaluasi PKL ditinjau dari pihak sekolah

\begin{tabular}{lccccc}
\hline \multicolumn{1}{c}{ Indikator } & $\begin{array}{c}\text { Skor } \\
\text { Perolehan }\end{array}$ & $\begin{array}{c}\text { Skor } \\
\text { Maksimal }\end{array}$ & $\begin{array}{c}\text { Ketercapaian } \\
(\%)\end{array}$ & $\begin{array}{c}\text { Penghambat } \\
(\%)\end{array}$ & Keterangan \\
\hline $\begin{array}{l}\text { Refleksi } \\
\text { PKL }\end{array}$ & 1897 & 2544 & 74,57 & 25,43 & Rendah \\
$\begin{array}{l}\text { Tindak } \\
\text { Lanjut }\end{array}$ & 1967 & 2528 & 77,81 & 22,19 & Rendah \\
PKL & & & & & Rendah \\
\hline \multicolumn{1}{c}{ Total } & 3864 & 5072 & 76,18 & 23,82 & R \\
\hline
\end{tabular}

Berdasarkan Tabel 4 total persentase indikator penghambat tahap evaluasi PKL ditinjau dari pihak sekolah 23,82\% kategori penghambat rendah, sehingga dapat dikatakan tidak ada penghambat. Faktor penghambat tahap perencanaan PKL ditinjau dari DU/DI disajikan pada Tabel 5.

Tabel 5. faktor peghambat tahap perencanaan PKL ditinjau dari DU/DI

\begin{tabular}{|c|c|c|c|c|c|}
\hline Indikator & $\begin{array}{c}\text { Skor } \\
\text { Perolehan }\end{array}$ & $\begin{array}{c}\text { Skor } \\
\text { Maksimal }\end{array}$ & $\begin{array}{c}\text { Ketercapaian } \\
(\%)\end{array}$ & $\begin{array}{c}\text { Penghambat } \\
(\%)\end{array}$ & $\begin{array}{l}\text { Keterangan } \\
\text { Penghambat }\end{array}$ \\
\hline $\begin{array}{l}\text { Kerjasama } \\
\text { antara Pihak } \\
\text { Sekolah } \\
\text { dengan } \\
\text { DU/DI }\end{array}$ & 118 & 168 & 70,24 & 29,76 & Rendah \\
\hline $\begin{array}{l}\text { Perencanaan } \\
\text { Waktu PKL }\end{array}$ & 110 & 168 & 65,48 & 34,52 & Rendah \\
\hline $\begin{array}{l}\text { Perencanaan } \\
\text { Kompetensi } \\
\text { (Pekerjaan } \\
\text { yang } \\
\text { Dilakukan } \\
\text { Selama PKL) }\end{array}$ & 113 & 168 & 67,26 & 32,74 & Rendah \\
\hline $\begin{array}{l}\text { Perencanaan } \\
\text { Akomodasi } \\
\text { Peserta PKL }\end{array}$ & 126 & 168 & 75,00 & 25,00 & Rendah \\
\hline $\begin{array}{l}\text { Pembekalan } \\
\text { Peserta PKL }\end{array}$ & 119 & 168 & 70,83 & 29,17 & Rendah \\
\hline Total & 586 & 840 & 69,76 & 30,24 & Rendah \\
\hline
\end{tabular}

Berdasarkan Tabel 5 total persentase indikator penghambat tahap perencanaan PKL ditinjau dari DU/DI 30,24\% kategori penghambat rendah, sehingga dapat dikatakan tidak ada penghambat. Faktor penghambat tahap pelaksanaan PKL ditinjau dari DU/DI disajikan pada Tabel 6. 
Tabel 6 Faktor Penghambat Tahap Pelaksanaan PKL Ditinjau dari DU/DI

\begin{tabular}{|c|c|c|c|c|c|}
\hline Indikator & $\begin{array}{c}\text { Skor } \\
\text { Perolehan }\end{array}$ & $\begin{array}{c}\text { Skor } \\
\text { Maksimal }\end{array}$ & $\begin{array}{c}\text { Ketercapaian } \\
(\%)\end{array}$ & $\begin{array}{l}\text { Penghambat } \\
(\%)\end{array}$ & Keterangan \\
\hline $\begin{array}{l}\text { Fasilitas } \\
\text { yang } \\
\text { diterima } \\
\text { peserta PKL } \\
\text { sesuai } \\
\text { dengan } \\
\text { Kompetensi } \\
\text { Keahlian }\end{array}$ & 116 & 168 & 69,05 & 30,95 & Rendah \\
\hline $\begin{array}{l}\text { Kompetensi } \\
\text { yang } \\
\text { Diterima } \\
\text { Peserta PKL }\end{array}$ & 105 & 168 & 62,50 & 37,50 & Rendah \\
\hline $\begin{array}{l}\text { Pelaksanaan } \\
\text { PKL }\end{array}$ & 101 & 168 & 60,12 & 39,88 & Cukup \\
\hline $\begin{array}{l}\text { Bimbingan } \\
\text { dan } \\
\text { Monitoring } \\
\text { yang } \\
\text { dilakukan } \\
\text { DU/DI }\end{array}$ & 109 & 168 & 64,88 & 35,12 & Rendah \\
\hline Total & 431 & 672 & 64,14 & 35,86 & Rendah \\
\hline
\end{tabular}

Berdasarkan Tabel 6 total persentase indikator penghambat tahap pelaksanaan PKL ditinjau dari DU/DI 35,86\% kategori penghambat rendah, sehingga dapat dikatakan tidak ada penghambat. Namun, pada indikator pelaksanaan PKL dengan persentase penghambat 39,88\% kategori penghambat cukup, sehingga dapat dikatakan ada penghambat dalam hal pelaksanaan PKL. Faktor penghambat tahap evaluasi PKL ditinjau dari pihak sekolah disajikan pada Tabel 7 .

Tabel 7 Faktor Peghambat Tahap Evaluasi PKL Ditinjau dari DU/DI

\begin{tabular}{lccccc}
\hline \multicolumn{1}{c}{ Indikator } & $\begin{array}{c}\text { Skor } \\
\text { Perolehan }\end{array}$ & $\begin{array}{c}\text { Skor } \\
\text { Maksimal }\end{array}$ & $\begin{array}{c}\text { Ketercapaian } \\
(\%)\end{array}$ & $\begin{array}{c}\text { Penghambat } \\
(\%)\end{array}$ & Keterangan \\
\hline $\begin{array}{l}\text { Refleksi } \\
\text { dan }\end{array}$ & & & & & \\
$\begin{array}{l}\text { Tindak } \\
\text { Lanjut }\end{array}$ & 83 & 168 & 49,40 & 50,60 & Cukup \\
PKL & & & & & \\
\hline \multicolumn{1}{c}{ Total } & 83 & 168 & 49,40 & 50,60 & Cukup \\
\hline
\end{tabular}

Berdasarkan Tabel 7 total persentase indikator penghambat tahap evaluasi PKL ditinjau dari DU/DI 50,60\% kategori penghambat cukup, sehingga dapat dikatakan ada penghambat.

Relevansi penempatan PKL merupakan kesesuaian bidang kompetensi ke- ahlian peserta $\mathrm{PKL}$ dengan tempat $\mathrm{PKL}$ di DU/DI yang mencakup dua variabel yaitu kesesuaian tempat dan kesesuaian bidang (Nidhom, dkk., 2015). Berdasarkan hasil penelitian didapatkan bahwa tingkat relevansi penempatan PKL di SMK seJombang dalam kategori rendah untuk 
kompetensi Teknik Komputer dan Jaringan serta Multimedia.

Berdasarkan hasil penelitian ditinjau dari pihak sekolah didapatkan bahwa pada perencanaan waktu PKL tidak ada penghambat, karena sebelumnya pihak sekolah melakukan komunikasi dan kesepakatan dengan DU/DI. Sebagaimana hasil penelitian Anik (dalam Hadi, 2017) yang menyatakan bahwa hubungan kerjasama direncanakan secara tepat oleh pihak sekolah dan DU/DI, agar dapat terselenggara dengan efektif dan efisien.

Perencanaan tempat PKL tidak ada penghambat, namun hasil wawancara dengan Pokja PKL menunjukkan bahwa terdapat sekolah yang mengalami kesulitan dalam mencari tempat PKL yang sesuai dengan kompetensi keahlian. Kesulitan perencanaan tempat PKL karena terbatasnya jumlah DU/DI yang sesuai dengan kompetensi keahlian peserta PKL dan banyaknya SMK di Jombang.

Sebagaimana penelitian Nidhom (2013) yang menyatakan bahwa ada hubungan yang signifikan antara kesesuaian tempat $\mathrm{PKL}$ dengan hasil $\mathrm{PKL}$ peserta didik kompetensi keahlian TKJ di SMK kota Batu, kesesuaian tempat PKL memberikan hasil positif terhadap hasil PKL.

Perencanaan akomodasi peserta PKL tidak ada penghambat. Adapun hasil wawancara dengan Pokja PKL menyatakan bahwa pihak sekolah tidak menyediakan akomodasi baik tempat tinggal maupun transportasi.

Pembekalan peserta PKL tidak ada penghambat, dikarenakan pihak sekolah selalu memberikan pembekalan pada peserta PKL yang meliputi peraturan kerja, orientasi pekerjaan, K3 dan kedisiplinan. Kerjasama antara pihak sekolah dengan DU/DI ada penghambat, berdasarkan hasil interview (wawancara) dengan Pokja PKL dalam pelaksanaan PKL menunjukan kerjasama hanya sebatas percakapan saja tanpa adanya ikatan resmi.

Hal tersebut sesuai dengan penelitian Anik dan Nayono (dalam Hadi, 2017) yang menyatakan bahwa pelaksanaan kerjasama harus dilakukan dengan kreatif, inovatif, dan saling bersinergi untuk saling mengisi untuk meningkatkan mutu pendidikan dan program PKL.

Fasilitas yang diterima peserta $\mathrm{PKL}$ sesuai dengan kompetensi keahlian tidak ada penghambat, karena semua peralatan yang ada di DU/DI sudah cukup lengkap. Kompetensi yang diterima peserta PKL menunjukkan ada penghambat, terdapat peserta PKL yang mengerjakan pekerjaan tidak sesuai dengan kompetensi keahliannya.

Bimbingan dan monitoring yang dilakukan pihak sekolah tidak ada penghambat, dikarenakan guru pembimbing melakukan monitoring minimal tiga kali selama masa PKL. Pelaksanaan PKL tidak ada penghambat, berdasarkan hasil wawancara dengan Pokja PKL menunjukkan bahwa yang mengetahui kesulitan PKL adalah peserta PKL sendiri.

Tahap evaluasi PKL merupakan tindak lanjut berkaitan dengan perencanaan dan pelaksanaan PKL untuk melakukan perbaikan pembelajaran pada masa yang akan datang (Surachim, 2016). Berdasarkan hasil penelitian pada refleksi dan tindak lanjut tidak ada penghambat, dikarenakan pihak sekolah selalu melakukan refleksi setelah pelaksanaan PKL dengan peserta PKL dan melakukan tindak lanjut berdasarkan permasalahan yang ada selama PKL.

Berdasarkan hasil penelitian ditinjau dari DU/DI didapatkan bahwa pada kerjasama antara pihak sekolah dengan DU/DI tidak ada penghambat, namun hasil wawancara dengan DU/DI menunjukkan bahwa kerjasama hanya sebatas percakapan saja tanpa adanya ikatan resmi. Sesuai dengan penelitian Azizah (dalam Hadi, 2017) yang menyatakan bahwa program kerjasama dengan DU/DI harus terus dibina secara berkesinambungan.

Perencanaan waktu PKL tidak ada penghambat, karena sebelumnya pihak sekolah melakukan komunikasi dan kesepakatan dengan DU/DI. Perencanaan kompetensi (pekerjaan yang dilakukan selama $\mathrm{PKL}$ ) tidak ada penghambat, namun hasil wawancara dengan DU/DI menunjukkan bahwa tugas yang dilakukan peserta PKL mengikuti pekerjaan sehari-hari yang ada di DU/DI. Sesuai dengan pedoman pelaksanaan PKL oleh 
Dikmenjur (2013) perencanaan kompetensi dilakukan untuk mengetahui kejelasan tentang topik-topik pembelajaran atau pekerjaan yang dapat dilakukan oleh peserta PKL dalam kegiatan PKL di DU/DI.

Perencanaan akomodasi peserta PKL tidak ada penghambat. Adapun hasil wawancara dengan DU/DI menyatakan bahwa DU/DI tidak menyediakan akomodasi baik tempat tinggal maupun transportasi. Pembekalan peserta PKL tidak ada penghambat, namun hasil wawancara dengan DU/DI menjukkan bahwa peserta PKL masih belum bisa beradaptasi dengan dunia kerja.

Fasilitas yang diterima peserta PKL sesuai dengan kompetensi keahlian tidak ada penghambat, karena semua peralatan yang ada di DU/DI sudah cukup lengkap. Sesuai dengan penelitian Wahono (2014) sarana belajar memegang peranan yang sangat penting dalam mendukung tercapainya keberhasilan belajar.

Kompetensi yang diterima peserta PKL tidak ada penghambat, karena peserta PKL mengerjakan tugas sesuai dengan kemampuannya. Tahap pelaksanaan PKL merupakan koordinasi pelaksanaan pembelajaran dan praktik kerja di DU/DI (Surachim, 2016). Bimbingan dan monitoring yang dilakukan tidak ada penghambat, namun hasil wawancara dengan DU/DI menunjukkan bahwa teori yang dipelajari di sekolah tidak sesuai dengan praktik di lapangan. Di dalam pelaksanaan PKL memerlukan bimbingan dari instruktur PKL yang intensif dan peserta PKL harus aktif karena peserta PKL yang mendapat bimbingan intensif dari guru pebimbing mempunyai kompetensi yang lebih baik daripada peserta PKL yang mendapat bimbingan tidak intensif (Efendi, dkk., 2012).

Pelaksanaan PKL ada penghambat, terdapat peserta PKL yang membolos dan terlambat pada saat PKL. Sebagaimana penelitian Susanti (2015) yang menyatakan bahwa kesesuaian tempat PKL dengan kompetensi peserta PKL akan menjadi faktor pendukung apabila tempat pelaksanaan dan bidang pekerjaan peserta PKL pada saat PKL sesuai dengan kompetensi keahliannya.
Refleksi dan tindak lanjut tidak ada hambatan, namun hasil wawancara dengan DU/DI menunjukkan bahwa tidak ada ujian atau evaluasi akhir yang dilakukan DU/DI dari jurnal harian yang dibuat peserta PKL. Padahal jurnal harian digunakan untuk crosscheck pekerjaan peserta $\mathrm{PKL}$ dengan kompetensi keahliannya. Hal tersebut relevan dengan penelitian Suwarman (2014) yang menyatakan bahwa buku jurnal yang telah diisi dengan lengkap oleh peserta PKL akan memudahkan peserta PKL untuk menyusun laporan pelaksanaan $\mathrm{PKL}$

Temuan hasil interview (wawancara) dengan pihak sekolah mengenai cara mengatasi faktor penghambat relevansi penempatan PKL antara lain: (a) melibatkan pihak DU/DI dalam penentuan kurikulum agar teori praktik di sekolah sesuai dengan praktik di DU/DI; (b) meningkatkan kerjasama dengan DU/DI; dan (c) meningkatkan intensitas pembimbingan peserta PKL oleh guru pembimbing.

Temuan hasil interview (wawancara) dengan DU/DI mengenai cara mengatasi faktor penghambat relevansi penempatan PKL antara lain: (a) mempertahankan dan meningkatkan produktifitas perusahaan; (b) Melaksanakan bimbingan secara terus menerus; dan (c) mengadakan evaluasi PKL.

\section{SIMPULAN DAN SARAN}

Kesimpulan dari penelitian ini adalah tingkat relevansi penempatan PKL di SMK se-Jombang untuk kompetensi keahlian Teknik Komputer dan Jaringan dalam kategori rendah. Faktor penghambat relevansi penempatan $\mathrm{PKL}$ ditinjau dari pihak sekolah di SMK se-Jombang adalah kerjasama antara pihak sekolah dengan DU/DI dan kompetensi yang diterima peserta PKL. Faktor penghambat relevansi penempatan PKL ditinjau dari DU/DI di SMK se-Jombang adalah pelaksanaan $P K L$, refleksi dan tindak lanjut.

Saran yang dianjurkan bagi pihak sekolah adalah diharapkan meningkatkan kerjasama dengan DU/DI yang sesuai dengan kompetensi keahlian. Diharapkan menganalisis Kompetensi Dasar (KD) dan topik pembelajaran atau pekerjaan pada 
mata pelajaran paket keahlian serta memetakannya berdasarkan kemungkinan atau peluang dilaksanakan pembelajaran topik-topik tersebut di masing-masing DU/DI.

Diharapkan melibatkan DU/DI dalam penentuan kurikulum agar teori dan praktik di sekolah relevan dengan praktik di DU/DI, sehingga DU/DI dapat memberikan pekerjaan dan tugas kepada peserta PKL sesuai dengan kompetensi keahlian. Diharapkan lebih memperhatikan pemilihan tempat $\mathrm{PKL}$ yang dapat memberikan kemungkinan atau peluang dilaksanakan pembelajaran topik-topik berdasarkan Kompetensi Dasar (KD) di masing-masing DU/DI agar peserta PKL nantinya dapat melaksanakan program $\mathrm{PKL}$ secara maksimal sesuai dengan tujuan PKL. Diharapkan meningkatkan intensitasnya untuk melakukan pembimbingan.

Saran yang dianjurkan bagi DU/DI adalah diharapkan tetap bisa mempertahankan dan meningkatkan produktifitas perusahaan agar tetap bisa bekerjasama dengan pihak sekolah, sehingga dari tahun ke tahun DU/DI dapat menambah jumlah peserta PKL karena sulitnya mencari tempat PKL yang sesuai dengan kompetensi keahlian.

Diharapkan dapat melaksanakan hasil pemetaan kemungkinan atau peluang dilaksanakan pembelajaran berdasarkan Kompetensi Dasar (KD) sesuai dengan kompetensi keahlian. Diharapkan melakukan evaluasi/ujian diakhir PKL untuk mengetahui kompetensi yang diterima peserta $\mathrm{PKL}$ selama pelaksanaan PKL.

\section{DAFTAR PUSTAKA}

Dikmenjur. 2013. Panduan Prakerin. (Online), (https://www.academia.edu/2784776 4/PRAKTIK_KERJA_LAPANGAN_P KL_SEKOLĀH_MENENGAH_KEJU RUAN), diakses pada 13 April 2018.

Efendi, S., Sutadji, E. \& Mukhadis, A. 2012. Pencapaian Kompetensi Prakerin Ditinjau dari Persepsi Siswa tentang Kualifikasi Tempat, Pembimbingan, dan Umpan Balik pada Keahlian Teknik Mesin SMK.
Jurnal Teknologi dan Kejuruan, 35(2), 115-124.

Fatchurrochman, R. 2011. Pengaruh Motivasi Berprestasi Terhadap Kesiapan Belajar, Pelaksanaan Prakerin dan Pencapaian Kompetensi Matapelajaran Produktif. Jurnal Pendidikan Vokasi, 7(2), 175188.

Dari http://ejournal.upi.edu/index.php/invo tec/article/view/6292/4259

Hadi, F. S., Mukhadis, A., \& Nyoto, A. 2017. Hambatan dan Faktor Penyebabnya Prakerin Ditinjau dari Persiapan, Pelaksanaan, dan Evaluasi Kompetensi Keahlian Teknik Pemesinan di SMK. Teknologi dan Kejuruan, 40(2), 99104.

Dari http://journal.um.ac.id/index.php/tekn ologikejuruan/article/view/10026/4763.

Hamalik, O. 2013. Dasar-dasar Pengembangan Kurikulum. Bandung: PT Remaja Rosadakarya Offset.

Iriani, D. S. \& Soeharto. 2015. Evaluasi Pelaksanaan Praktik Kerja Industri Siswa Kompetensi Keahlian Jasa Boga SMK N 3 Purworejo. Jurnal Pendidikan Teknologi dan Kejuruan, 22(3), 2015, 274-290. Dari https://journal.uny.ac.id/index.php/jpt k/article/view/6835.

Keputusan Menteri Pendidikan dan Kebudayaan Indonesia No. 323/U/1997 tentang Pendidikan Sistem Ganda.

Mangkunegara, A. P. 2003. Perencanaan dan Pengembangan Sumber Daya Manusia. Bandung: PT Refika Aditama.

Nidhom, A. M., Sonhadji, A., dan Sudjimat, D. A. 2015. Hubungan Kesiapan Belajar, Lama Pembelajaran, Kesesuaian Tempat dan Partisipasi DU/DI dengan Hasil Prakerin Peserta Didik Kompetensi Keahlian TKJ di SMK Kota Batu. Jurnal Pendidikan, 9(1), 1-14. Dari 
http://jurnal.upi.edu/file/01_Ahmad_ Mursyidun_Nidhom_1-14.pdf.

Prasetyo, B. 2013. Evaluasi Pelaksanaan Praktik Kerja Industri Kompetensi Keahlian Teknik Gambar Bangunan SMK N 2 Klaten. Jurnal Pendidikan Vokasi, 3(1): 78-91.

Putriatama, E., Patmanthara, S., \& Sugandi, R. M. 2016. Kontribusi Pengalaman Prakerin, Wawasan Dunia Kerja dan Kompetensi Kejuruan Melalui Employability Skill Serta Dampaknya Terhadap Kesiapan Kerja Lulusan SMK Kompetensi Keahlian Teknik Komputer dan Jaringan di Probolinggo. Jurnal Pendidikan, 1(8), 15-45. Dari http://journal.um.ac.id/index.php/jptp p/article/view/6643.

Reiser, R. H \& Gagne, R. M. 1982. Characteristics Media Selection Model. Revies of Educational Research. 52. (4), 499-512.

Setianingtyas, C. R. \& Putro, S. C. 2013. Hubungan Tingkat Kompetensi TKJ dan Relevansi Praktik Kerja Industri terhadap Minat Kerja dibidang TKJ pada Siswa Program Keahlian TKJ Di SMK Kabupaten Magetan. TEKNO, 20(1), 1693-8739. Dari journal.um.ac.id.

Starr. 1986. Improving Teaching. Columbus: The National Center For Research in Vocational Education.

Susanti, A.I. 2015. Kontribusi Persepsi Siswa tentang Kualitas Guru, Kesesuaian, dan Hasil Prakerin terhadap Pemployability Skills Siswa SMK. Jurnal Teknologi dan Kejuruan, 38(2), 121-132.

Surachim, A. 2016. Efektivitas Pembelajaran Pola Pendidikan Sistem Ganda. Bandung: Alfabeta.

Suwarman. 2014. Pengelolaan Praktik Kerja Industri pada Program Keahlian Teknik Pemesinan SMK Se-Kabupaten Kulon Progo. Jurnal Pendidikan Vokasi, 4(1), 25-34. Dari https://journal.unnes.ac.id/sju/index. php/jmel/article/view/4493.

UU RI No. 20 Tahun 2003 tentang Sistem Pendidikan Nasional

Widyasari, W. C. 2017. Hubungan Antara Kompetensi Keahlian dan Kesesuaian Praktik Kerja Industri terhadap Kesiapan Memasuki Dunia Kerja. Skripsi tidak diterbitkan: Malang: Universitas Negeri Malang.

Wahono, W. 2014. Kualitas Pembelajaran Siswa SMK Ditinjau dari Fasilitas Belajar. Jurnal IImiah Guru "COPE", 01(18): 66-71. 